Polymer Journal, Vol. 38, No. 12, pp. 1258-1266 (2006)

(C)2006 The Society of Polymer Science, Japan

\title{
Helix-Sense-Selective Radical Polymerization of $N$-(Triphenylmethyl)methacrylamides and Properties of the Polymers
}

\author{
Naohiro HoshiKawa, Chiyo Yamamoto, Yuji HоттA, and Yoshio Oкамото \\ Department of Applied Chemistry, Graduate School of Engineering, Nagoya University, \\ Furo-cho, Chikusa-ku, Nagoya 464-8603, Japan
}

(Received July 31, 2006; Accepted September 28, 2006; Published November 2, 2006)

\begin{abstract}
N$-(Triphenylmethyl)methacrylamide (TrMAM) and $N$-[di(4-butylphenyl)-phenylmethyl]methacrylamide (DBuTrMAM) were polymerized using a radical initiator. The obtained poly(TrMAM) was insoluble in common organic solvents, but poly(DBuTrMAM) was soluble in chloroform and THF. Both polymers were dissolved in conc. $\mathrm{H}_{2} \mathrm{SO}_{4}$ accompanied by cleavage of the side groups to give poly(methacrylamide) (poly(MAM)). The ${ }^{1} \mathrm{H}$ NMR of the polymers in $\mathrm{D}_{2} \mathrm{SO}_{4}$ indicated that the polymers obtained at low temperature were nearly $100 \%$ isotactic. The poly(MAM) with almost $100 \%$ isotacticity showed a crystallinity. The poly(DBuTrMAM) formed a lyotropic crystalline phase in chloroform. The radical polymerization of the monomers in the presence of various chiral additives produced optically active polymers having a prevailing helicity. The optically active poly(TrMAM) exhibited a low chiral recognition. [doi:10.1295/polymj.PJ2006087]

KEY WORDS Methacrylamide / Helicity / Optically Active Polymer / Chiral Recognition / Isotactic Polymer /
\end{abstract}

The stereoregularity of a polymer often significantly influences the properties and functions of the polymer, and its control is of importance in polymer science and industry. ${ }^{1}$ Radical polymerization often produces atactic or slightly syndiotactic-rich polymers, and is not sensitive to the polymerization conditions, such as solvents and temperature. ${ }^{2}$ Therefore, the tacticity control during polymerization has been attained only for a limited number of monomers. For example, vinyl acetate yields a syndiotactic-rich polymer in fluoroalcohols due to electrostatic repulsion among the fluoroalcohols coordinating to the monomer. ${ }^{3}$ Acrylamides and methacrylamides yield isotactic-rich polymers by the radical process in the presence of a Lewis acid such as ytterbium trifluoromethanesulfonate $\left(\mathrm{Yb}(\mathrm{OTf})_{3}\right) .{ }^{4}$ The radical polymerization of the methacrylates with a bulky side group like triphenylmethyl methacrylate (TrMA) also proceeds in an isotactic-specific manner due to steric repulsion among the bulky side groups. ${ }^{5}$ The isotactic poly(TrMA) is a mixture of left- and right-handed helices. The one-handed helical poly(TrMA) has been prepared by the asymmetric anionic polymerization using a chiral anionic initiator, and the optically active poly(TrMA) has an excellent chiral recognition ability as a chiral stationary phase for high performance liquid chromatography (HPLC). ${ }^{6}$ However, the ester groups of poly(TrMA) are solvolyzed by methanol used as an eluent for HPLC, and the polymer slowly loses its chiral recognition ability. Recently, we found that the radical polymerization of $N$-(triphenylmethyl)methacrylamide (TrMAM) also proceeded in an isotactic-specific manner ( $\mathrm{mm}>99 \%$ ), and a prevailing one-handed helical polymer has been obtained in the presence of the optically active (+)- and (-)-menthol. ${ }^{7}$ TrMAM is not solvolized in methanol. This suggests that the optically active poly(TrMAM) might be used as a more stable chiral stationary phase for HPLC. In the present study, the radical polymerizations of TrMAM and $N$-[di(4-butylphenyl)phenylmethyl]methacrylamide (DBuTrMAM) were carried out in the presence of various optically active additives, and the chiral recognition ability of the obtained optically active poly(TrMAM) was investigated. The properties of the highly isotactic poly(methacrylamide) (poly(MAM)) derived from poly(TrMAM) and poly(DBuTrMAM) were also studied.

\section{EXPERIMENTAL}

\section{Materials}

TrMAM. In a $500 \mathrm{~mL}$ three-neck flask equipped with a condenser and a dropping funnel, triphenylmethylamine $(9.0 \mathrm{~g}, 0.03 \mathrm{~mol})$ dissolved in dry chloroform $(125 \mathrm{~mL})$ and triethylamine $(10 \mathrm{~mL}, 0.07 \mathrm{~mol})$ were added under an $\mathrm{N}_{2}$ atmosphere, and then methacryloyl chloride $(3.9 \mathrm{~mL}, 0.04 \mathrm{~mol})$ dissolved in chloroform $(25 \mathrm{~mL})$ was dropwise added with stirring

\footnotetext{
${ }^{\dagger}$ To whom correspondence should be addressed (E-mail: okamoto@ apchem.nagoya-u.ac.jp).

${ }^{\dagger \dagger}$ Present Address: EcoTopia Science Institute, Nagoya University, Furo-cho, Chikusa-ku, Nagoya 464-8603, Japan
} 
at $0{ }^{\circ} \mathrm{C}$ for $1 \mathrm{~h}$. The reaction was then continued for $20 \mathrm{~h}$ at room temperature. The reaction mixture was washed three times with a saturated aqueous solution $(400 \mathrm{~mL})$ of $\mathrm{NaHCO}_{3}$ and twice with water. The solution was dried over $\mathrm{Na}_{2} \mathrm{SO}_{4}$ and evaporated. The product was recrystallized from a mixture of hexane and ethyl acetate. Yield $5.0 \mathrm{~g}(0.015 \mathrm{~mol}, 52 \%, \mathrm{mp}$ $\left.134,138^{\circ} \mathrm{C}\right) .{ }^{1} \mathrm{H} \mathrm{NMR}\left(400 \mathrm{MHz}, \mathrm{CDCl}_{3}, 25^{\circ} \mathrm{C}\right) \delta$ 7.20-7.32 (m, 15H, aromatic $\mathrm{H}), 6.98(\mathrm{~s}, 1 \mathrm{H}, \mathrm{NH})$, 5.35, $5.71(\mathrm{~m}, 2 \mathrm{H}$, vinyl $\mathrm{H}), 1.98(\mathrm{q}, 3 \mathrm{H}, J=0.9$, $\left.1.2, \alpha-\mathrm{CH}_{3}\right)$. IR $(\mathrm{KBr}) 1665 \mathrm{~cm}^{-1}(\mathrm{C}=\mathrm{O}), 1629 \mathrm{~cm}^{-1}$ $(\mathrm{C}=\mathrm{C})$. Anal. Calcd for $\mathrm{C}_{23} \mathrm{H}_{21} \mathrm{NO}$ : $\mathrm{C}, 84.37 ; \mathrm{H}, 6.46$; N, 4.27. Found: C, 84.36; H, 6.40; N, 4.37.

DBUTrMAM. DBuTrMAM was synthesized in a manner similar to that for TrMAM. Di(4-butylphenyl)phenylmethylamine $(3.0 \mathrm{~g}, 8.0 \mathrm{mmol})$ was used instead of triphenylmethylamine. The reaction with methacryloyl chloride was then conducted for $2 \mathrm{~h}$ at $0{ }^{\circ} \mathrm{C}$ and $24 \mathrm{~h}$ at room temperature. The reaction mixture was washed with a saturated aqueous $\mathrm{NaHCO}_{3}$ solution and water. The product was purified by silica gel column chromatography (hexane). The monomer was a viscous oil, and readily polymerized at room temperature. Therefore, it was stored as a hexane solution at $-20^{\circ} \mathrm{C} .{ }^{1} \mathrm{H}$ NMR $\left(400 \mathrm{MHz}, \mathrm{CDCl}_{3}, 25^{\circ} \mathrm{C}\right)$ $\delta 7.09-7.28(\mathrm{~m}, 13 \mathrm{H}$, aromatic $\mathrm{H}), 6.94(\mathrm{~s}, 1 \mathrm{H}, \mathrm{NH})$, 5.33, $5.70(\mathrm{~m}, 2 \mathrm{H}$, vinyl $\mathrm{H}), 2.58(\mathrm{t}, 4 \mathrm{H}, J=7.8$, $-\mathrm{CH}_{2} \mathrm{CH}_{2} \mathrm{CH}_{2} \mathrm{CH}_{3}$ ), 1.97 (q, 3H, $J=0.91 .2, \alpha-\mathrm{CH}_{3}$ ), $1.59\left(\mathrm{~m}, 4 \mathrm{H},-\mathrm{CH}_{2} \mathrm{CH}_{2} \mathrm{CH}_{2} \mathrm{CH}_{3}\right), 1.35\left(\mathrm{~m}, 4 \mathrm{H},-\mathrm{CH}_{2}-\right.$ $\left.\mathrm{CH}_{2} \mathrm{CH}_{2} \mathrm{CH}_{3}\right), \quad 0.92 \quad\left(\mathrm{t}, \quad 6 \mathrm{H}, \quad J=7.2-\mathrm{CH}_{2} \mathrm{CH}_{2}-\right.$ $\left.\mathrm{CH}_{2} \mathrm{CH}_{3}\right)$. IR ( $\left.\mathrm{KBr}\right) 1684 \mathrm{~cm}^{-1}(\mathrm{C}=\mathrm{O}), 1630 \mathrm{~cm}^{-1}$ $(\mathrm{C}=\mathrm{C})$. FAB-MS Calcd for $\mathrm{C}_{31} \mathrm{H}_{37} \mathrm{NO}: \mathrm{m} / z$ 439, Found: $m / z 439$.

Optically Active Additives. Optically active compounds 1-17 (Scheme 1) were purchased from commercial sources: $(1 S, 2 S)-N, N^{\prime}$-bis[3-oxo-2-(2,4,6-trimethylbenzoyl)-butylidene]-1,2-diphenyl-ethylenediaminato cobalt(II) $((S)$-MPAC) $(\mathrm{TCI}),(+)$-neomenthol (TCI, >96\%), (+)-isomenthol (Aldrich, 99\%), 1 [(S)-(+)-2-butanol (Aldrich, 99\%)], 2 [(R)-(-)-2-heptanol (Aldrich, 95\%)], 3 [(R)-(-)-2-octanol (AZmax, $>98 \%,>99 \%$ e.e.)], 4 [(+)-menthol (TCI, >99.0\%)], 5 [(-)-menthol (Kishida, 99\%)], 6 [((1S)-endo)-(-)borneol (Aldrich, 98\%)], 7 [(1R)-endo-(+)-fenchyl alcohol (Aldrich, 96\%)], 8 [(1S,2S,3S,5R)-(+)-iso pinocampheol (Aldrich, 98\%)], 9 [(1S,2S,5S)-(-)-2hydroxy-3-pinanone (Aldrich, 99\%)], 10 [(S)-(+)-3hydroxytetrahydrofuran (Aldrich, 99\%)], 11 [(S)(-)- $\beta$-hydroxy- $\gamma$-butyrolactone (Aldrich, 96\%)], 12 [(+)-epiandrosterone (TCI, >97\%)], 13 [(+)-dihydrocholesterol (SIGMA, 95\%)], 14 [(S)-(+)-2-methylbutyric acid (Aldrich, 98\%)], 15 [(1S)-(-)-camphanic acid (Aldrich, 99\%)], 16 [(S)-(+)-5-oxo-2-tetrahydrofurancarboxylic acid (Aldrich, 98\%)], $17[(R)-(+)-$ tetrahydro-2-furoic acid (Aldrich, 99\%)]. (+)-Neo-

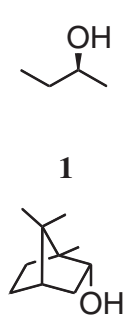

6

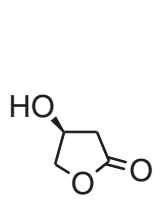

11<smiles>CCC(C)C(=O)O</smiles>

14

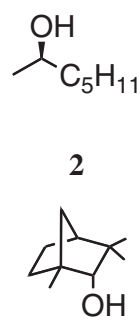

7
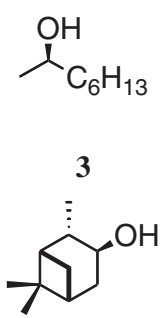

8
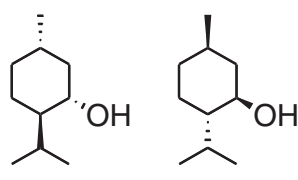

4

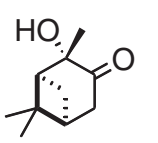

5

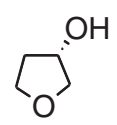

10

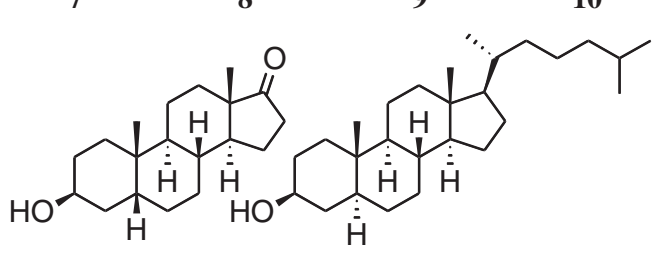

12

13

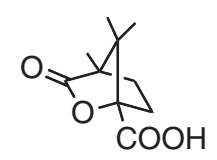

15

17

Scheme 1.

menthol, 1-3, 10, 14, and 17 were distilled under reduced pressure before use, while the other compounds were used without purification.

Initiators and Solvents. AIBN (Kishida, 99\%) was recrystallized from methanol. $n-\mathrm{Bu}_{3} \mathrm{~B}$ (Aldrich, $1.0 \mathrm{M}$ in tetrahydrofuran) was used without purification. Dehydrated toluene (Kanto, >99.5\%) and dehydrated tetrahydrofuran (THF) (Kanto, >99.5\%) were used as received.

\section{Polymerization}

The polymerization was carried out in a glass ampoule equipped with a three-way cock under a dry nitrogen atmosphere. In a typical example of the polymerization, TrMAM $(0.4 \mathrm{~g}, 1.22 \mathrm{mmol})$, AIBN $(8.0 \mathrm{mg}, 0.049 \mathrm{mmol})$, and a solvent $(2 \mathrm{~mL})$ were placed in the ampoule at room temperature, and heated at $60^{\circ} \mathrm{C}$. The polymerization using AIBN as the initiator at $-20 \sim 40^{\circ} \mathrm{C}$ was initiated by irradiating with UV light ( $400 \mathrm{~W}$ high-pressure mercury lamp). The polymerization using $n-\mathrm{Bu}_{3} \mathrm{~B}(0.013 \mathrm{~mL})$ as the initiator at $-40^{\circ} \mathrm{C}$ was initiated by adding air $(5 \mathrm{~mL})$ to the ampoule. ${ }^{8}$ In a two-necked conical flask, DBuTrMAM in hexane was added and then nitrogen gas was bubbled through it. The hexane was removed by evaporation under a reduced pressure at $0{ }^{\circ} \mathrm{C}$, and a polymerization solvent was added. This evaporation and addition of the solvent were repeated until the hexane had been fully replaced. A DBuTrMAM solution and liquid materials $\left(n-\mathrm{Bu}_{3} \mathrm{~B}\right.$, chiral additive, and solvent) were added to the ampoule by a syringe and TrMAM, AIBN, and a solid chiral additive were add- 
ed to the ampoule through a funnel having an $\mathrm{N}_{2}$ gas inlet tube. The polymerization solution was maintained at the prescribed temperature for $24 \mathrm{~h}$. The polymerization was terminated by cooling the reaction mixture to $-78^{\circ} \mathrm{C}$ and the reaction product was precipitated in methanol. The polymer was collected by centrifugation and dried in vacuo at $60^{\circ} \mathrm{C}$.

\section{Transformation of Poly(TrMAM) to Poly(MAM)}

Poly(TrMAM) $(0.5 \mathrm{~g} 1.5 \mathrm{mmol})$ was dissolved in conc. $\mathrm{H}_{2} \mathrm{SO}_{4}(1.8 \mathrm{~mL})$ at $-78^{\circ} \mathrm{C}$. The solution was poured to a large excess of methanol $(300 \mathrm{~mL})$ at $-78^{\circ} \mathrm{C}$ to precipitate the poly(MAM). The obtained poly(MAM) was collected by centrifugation, repeatedly washed with methanol, and dried in vacuo at $60{ }^{\circ} \mathrm{C}$.

\section{Molecular Model of PTrMAM}

Charges on the atoms were calculated using the Charge Equilibration (QEq) method $^{9}$ in CERIUS; ${ }^{2}$ the total charges of the molecules were zero. Molecular mechanics calculations were performed with the Dreiding forcefield (version 2.1.1) ${ }^{10}$ as implemented in the CERIUS ${ }^{2}$ software (version 4.2, MSI) ${ }^{11}$ running on an Octane work station (Silicon Graphics). The energy minimization of every molecular model was done by Conjugate Gradient until the root mean square value became less than $0.01 \mathrm{kcal} \mathrm{mol}^{-1} \AA^{-1}$.

\section{Chiral Adsorption}

The optically active polymers synthesized in the presence of (+)-menthol, (-)-menthol, or (+)-neomenthol were used to evaluate their chiral recognition ability. The polymer $(20 \mathrm{mg})$ was placed in a $0.3 \mathrm{~mL}$ screw-capped glass vial. A solution of a racemic compound in methanol or isooctane $(200 \mu \mathrm{L}$, conc. $=$ $0.25 \mathrm{~g} \mathrm{~L}^{-1}$ ) was added to the polymer. The mixture was allowed to stand for $3 \mathrm{~h}$ in a tightly capped container. The e.e. of the analyte in the sample solution was analyzed using the supernatant solution $(10 \mu \mathrm{L})$ by an HPLC system equipped with a JASCO UV970 UV detector, a JASCO OR-990 polarimeter, and a Daicel Chiralcel OD column $(25 \mathrm{~cm} \times 0.46 \mathrm{~cm}$ (i.d.)).

The separation factor $(\alpha)$ was determined by the following equation where the superscripts ' $\mathrm{f}$ ' and 'ads' denote the free (in solution part) and adsorbed (on the polymer), respectively: ${ }^{12}$

$$
\begin{aligned}
& \alpha=\frac{\left(\text { major antipode }^{\mathrm{f}}(\%)\right) /\left(\text { minor antipode }^{\mathrm{f}}(\%)\right)}{\left(\text { major antipode }^{\text {ads }}(\%)\right) /\left(\text { minor } \text { antipode }^{\text {ads }}(\%)\right)}
\end{aligned}
$$

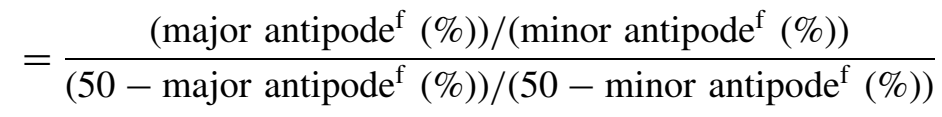

where

$$
\begin{aligned}
& \text { major antipode }^{\mathrm{f}}(\%)=(100-\text { adsorption yield }(\%)) \times\left(100+\text { e.e. }{ }^{\mathrm{f}} \mid\right) / 2 \times 1 / 100 \\
& \text { minor antipode }^{\mathrm{f}}(\%)=(100-\text { adsorption yield }(\%)) \times\left(100-\mid \text { e.e. }{ }^{\mathrm{f}} \mid\right) / 2 \times 1 / 100
\end{aligned}
$$

\section{Solvolysis of TrMAM}

The solvolysis reaction of TrMAM was carried out in a mixture of $\mathrm{CD}_{3} \mathrm{OD}$ and $\mathrm{CDCl}_{3}(=1 / 1(\mathrm{v} / \mathrm{v}))$ at $35^{\circ} \mathrm{C}$ in an NMR sample tube $(5 \mathrm{~mm} \phi)$ (Wilmad 507-PP). ${ }^{12}$ The reaction was monitored by ${ }^{1} \mathrm{H}$ NMR spectroscopy at $35^{\circ} \mathrm{C}$. TrMAM $(0.16 \mathrm{~g}, 0.5 \mathrm{mmol})$ was dissolved in $\mathrm{CDCl}_{3}(0.5 \mathrm{~mL})$ and the solution was placed in a water bath at $35^{\circ} \mathrm{C} . \mathrm{CD}_{3} \mathrm{OD}(0.5 \mathrm{~mL})$ was added to the solution in the NMR tube, which was immediately placed in the NMR instrument $(400 \mathrm{MHz})$ at $35^{\circ} \mathrm{C}$.

\section{Measurements}

The ${ }^{1} \mathrm{H}$ NMR spectra of the polymers were measured using a Varian Gemini 2000 spectrometer $(400 \mathrm{MHz})$ in $\mathrm{D}_{2} \mathrm{SO}_{4}$ at $60^{\circ} \mathrm{C}$. The microscopic images were observed using a Nikon OPTIPHOT-POL polarized optical microscope at room temperature. Size-exclusion chromatography (SEC) was performed by a JASCO PU-986 chromatograph equipped with a JASCO RI-930 detector using TSKgel $\mathrm{GMH}_{\mathrm{HR}}-\mathrm{H}$ and G3000HR columns connected in series (eluent $=$ THF; temperature $=40^{\circ} \mathrm{C}$ ). Calibration was performed using standard polystyrenes. The circular dichroism (CD) spectra were measured with a JASCO J-720L apparatus at room temperature. The polymer sample was ground in a mortar, dispersed in liquid paraffin, and interposed between two quartz plates for the $\mathrm{CD}$ measurements. ${ }^{13}$

\section{RESULTS AND DISCUSSION}

\section{Radical Polymerization of TrMAM}

The radical polymerization of TrMAM was carried out in THF or toluene in the temperature range from -40 to $60^{\circ} \mathrm{C}$ (Table I). In the all polymerizations, the polymer was obtained in a good yield.

The obtained poly(TrMAM) was insoluble in the 
Table I. Radical polymerization of TrMAM ${ }^{\mathrm{a}}$

\begin{tabular}{ccrlc}
\hline Run & Solvent & $\begin{array}{c}\text { Temp. } \\
\left({ }^{\circ} \mathrm{C}\right)\end{array}$ & Initiator & $\begin{array}{c}\text { Yield }^{\mathrm{b}} \\
(\%)\end{array}$ \\
\hline 1 & THF & -40 & $n$-Bu 3 B /air & 81 \\
2 & THF & -20 & AIBN/UV & 69 \\
3 & Toluene & 0 & AIBN/UV & 89 \\
4 & THF & 0 & AIBN/UV & 79 \\
5 & THF & 20 & AIBN/UV & 85 \\
6 & Toluene & 60 & AIBN & 85 \\
7 & THF & 60 & AIBN & 85 \\
\hline
\end{tabular}

${ }^{\mathrm{a}}[\text { TrMAM }]_{0}=0.5 \mathrm{~mol} / \mathrm{L},[\text { Initiator }]_{0}=0.02 \mathrm{~mol} / \mathrm{L}$, time $=$ $48 \mathrm{~h}$ (Run 1), $24 \mathrm{~h}$ (Runs 2-7). ${ }^{\mathrm{b}} \mathrm{MeOH}-$ insoluble part.

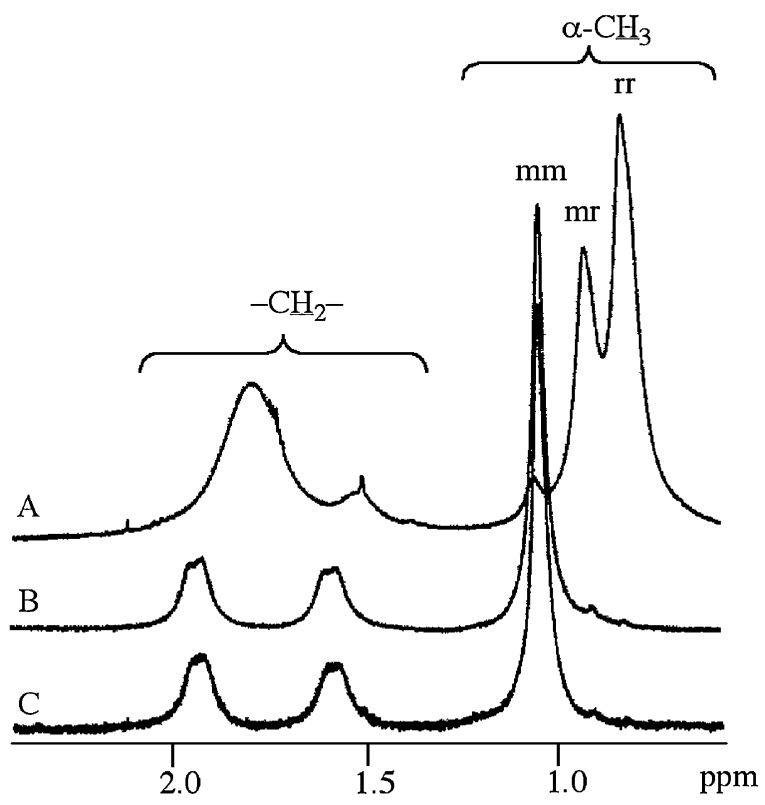

Figure 1. ${ }^{1} \mathrm{H}$ NMR spectra of PMAMs (A; obtained in methanol at $60^{\circ} \mathrm{C}$ : B; derived from PTrMAM (Run 3 in Table I): C; derived from PTrMAM (Run 4 in Table I)) (in $\mathrm{D}_{2} \mathrm{SO}_{4}$ at $60^{\circ} \mathrm{C}$ ).

common organic solvents, but was dissolved in conc. $\mathrm{H}_{2} \mathrm{SO}_{4}$ to give poly(methacrylamide) (poly(MAM)) accompanied by scission of the trityl groups. As the tacticity of poly(MAM) can be determined by ${ }^{1} \mathrm{H}$ NMR, ${ }^{14}$ poly(TrMAM) was analyzed by ${ }^{1} \mathrm{H}$ NMR spectroscopy after the polymer was converted to poly(MAM) in $\mathrm{D}_{2} \mathrm{SO}_{4}{ }^{7}$ The ${ }^{1} \mathrm{H}$ NMR spectra in $\mathrm{D}_{2} \mathrm{SO}_{4}$ at $60^{\circ} \mathrm{C}$ are shown in Figure 1. For comparison, the spectrum of the poly(MAM) obtained by the radical polymerization of methacrylamide in methanol at $60{ }^{\circ} \mathrm{C}$ is also shown. The spectra of $\mathrm{B}$ and $\mathrm{C}$ are for the poly(MAM)s derived from poly(TrMAM)s (Run 3 and Run 4 in Table I, respectively). These spectra indicate that the poly(TrMAM)s are nearly $100 \%$ isotactic and the tacticity was not influenced by the solvents used for the radical polymerization of TrMAM.

Figure 2 shows the ${ }^{1} \mathrm{H}$ NMR spectra of the polymers obtained at $-40^{\circ} \mathrm{C}$ and $60^{\circ} \mathrm{C}$. The lower temperature appears more suitable for obtaining the poly-

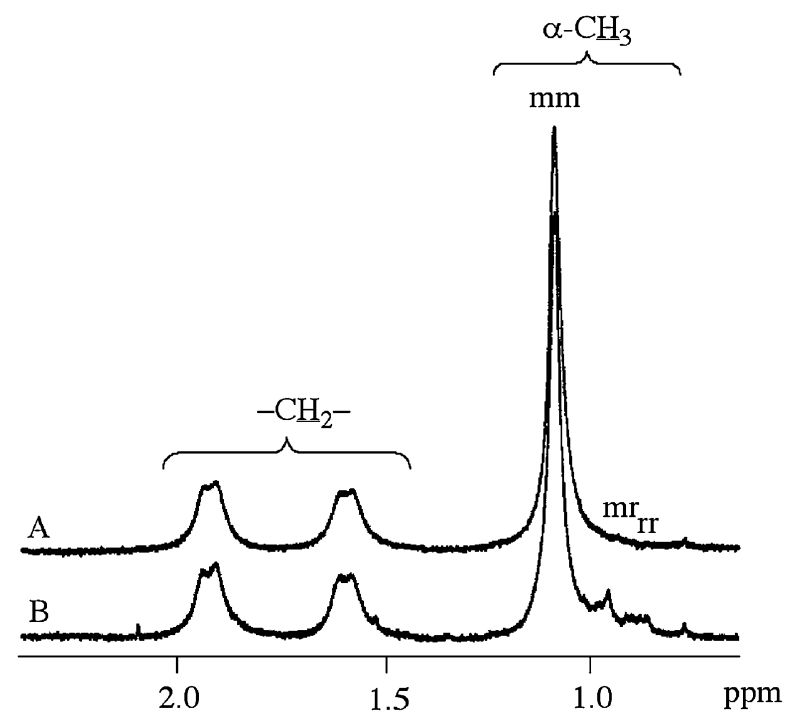

Figure 2. ${ }^{1} \mathrm{H}$ NMR spectra of PMAMs derived from PTrMAMs (A; Run 1 in Table I: B; Run 7 in Table I) (in $\mathrm{D}_{2} \mathrm{SO}_{4}$ at $\left.60^{\circ} \mathrm{C}\right)$.

Table II. Radical polymerization of DBuTrMAM at $0^{\circ} \mathrm{C}^{\mathrm{a}}$

\begin{tabular}{ccccc}
\hline Run & Solvent & $\begin{array}{c}\text { Yield }^{\mathrm{b}} \\
(\%)\end{array}$ & $\begin{array}{c}M_{\mathrm{n}}{ }^{\mathrm{c}} \\
\left(\times 10^{4}\right)\end{array}$ & $M_{\mathrm{w}} / M_{\mathrm{n}}{ }^{\mathrm{c}}$ \\
\hline 1 & THF & 64 & 7.4 & 3.7 \\
2 & Toluene & 82 & 18.3 & 7.8 \\
3 & ${\text { Toluene } /(-)-M e n t h o l^{\mathrm{d}}}^{2}$ & 90 & 56.0 & 17 \\
\hline \multicolumn{2}{c}{ a Data were cited from ref 13} & [Monomer] $]_{0}=0.5 \mathrm{~mol} / \mathrm{L}$,
\end{tabular}

${ }^{\mathrm{a} D a t a}$ were cited from ref 13 . [Monomer $]_{0}=0.5 \mathrm{~mol} / \mathrm{L}$, $[\mathrm{AIBN}]_{0}=0.02 \mathrm{~mol} / \mathrm{L}$, initiator: AIBN/UV, time: $24 \mathrm{~h} .{ }^{\mathrm{b}} \mathrm{Hex}-$ ane-insoluble part. ${ }^{\mathrm{c}}$ Determined by SEC in THF at $40{ }^{\circ} \mathrm{C}$ (polystyrene standard). ${ }^{\mathrm{d}}$ Toluene/menthol $=1 / 100(\mathrm{v} / \mathrm{v})$.

mer with a higher isotacticity, although the difference is not significant.

\section{Radical Polymerization of DBuTrMAM}

The radical polymerization of DBuTrMAM was carried out in THF, toluene, or a mixture of toluene/(-)-menthol $(=1 / 100(\mathrm{v} / \mathrm{v}))$ as shown in Table II. The obtained poly(DBuTrMAM)s were soluble in THF and chloroform in contrast to the poly(TrMAM). We also found that $\operatorname{poly}(N$-[(4-butyl)triphenylmethyl]methacrylamide) obtained by radical polymerization is also highly isotactic and soluble in these solvents. ${ }^{15}$ The molecular weight distribution of the poly(DBuTrMAM)s, particularly the high molecular weight polymer, was very broad. This may partly be due to the association of the poly(DBuTrMAM) chains.

Properties of Isotactic Poly(MAM) and Poly(DBuTrMAM)

The polarized optical micrograph of the isotactic poly(MAM) derived from poly(TrMAM) with a nearly $100 \%$ isotacticity is shown in Figure 3 . The isotac- 


\section{N. HoshiKaWA et al.}

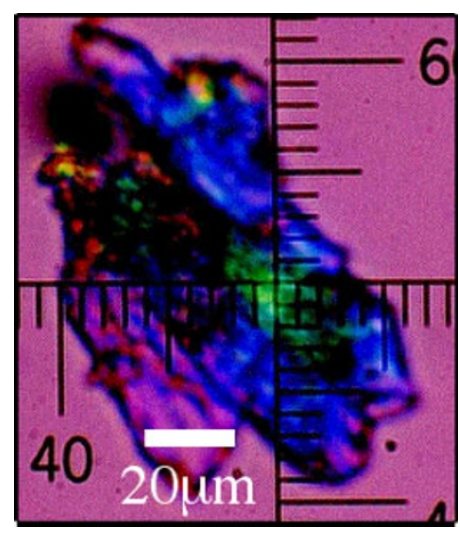

Figure 3. A polarized optical micrograph of isotactic-poly(MAM) (at r.t.).

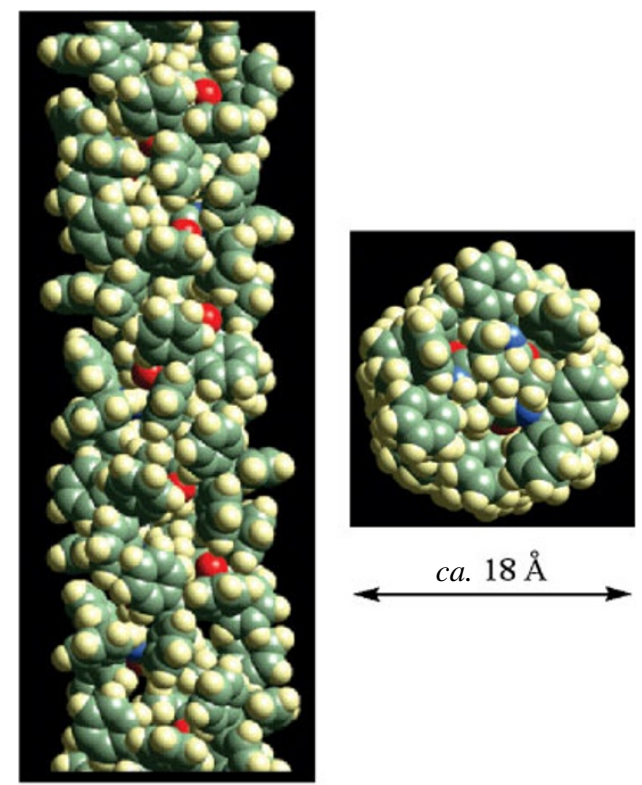

Figure 4. A possible structure (7/2 helix) of PTrMAM.

tic poly(MAM) exhibited a partial crystallinity, although the original poly(TrMAM) and the radically obtained syndiotactic poly(MAM) did not show clear crystallinity.

One of the possible structures of the isotactic poly(TrMAM) obtained by computer simulation is shown in Figure 4. The polymer has a right-handed $(7 / 2)$ helical structure similar to the poly(methacrylate) with a bulky ester group, poly(diphenyl(2-pyridyl)methyl methacrylate). ${ }^{16}$ The polymer has a rigid rod shape. From this model, the length of 28-mer is estimated to be about $7.5 \mathrm{~nm}$, with the diameter of $1.8 \mathrm{~nm}$.

Among the three polymers in Table II, only the low molecular weight polymer (Run 1) showed a lyotropic liquid crystallinity in chloroform. The polymers chains with a higher molecular weight may be difficult to be regularly arranged in solution. Figure 5 exhibits the polarized optical micrographs of poly(DBuTrMAM) (Run 1 in Table II) in chloroform. The poly-

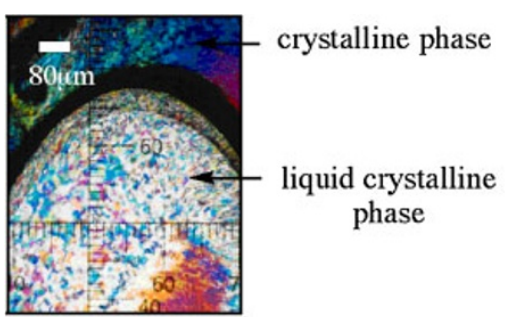

A

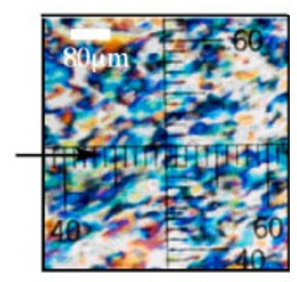

B
Figure 5. A polarized optical micrograph of poly(DBuTrMAM) (Run 1 in Table II) in chloroform (A: $9.1 \mathrm{wt} \%$, B: 16.7 wt \%) (at r.t.).

(DBuTrMAM) showed a lyotropic liquid crystallinity in chloroform at $9.1 \mathrm{wt} \%$ and $16.7 \mathrm{wt} \%$.

\section{Radical Polymerization of TrMAM in the Presence of Optically Active Additives}

The triphenylmethyl methacrylate derivatives form one-handed helical polymers by the anionic polymerization using the $n$-BuLi complex with a chiral ligand such as (-)-sparteine. ${ }^{17}$ The methacrylates also afford the prevailing one-handed helical polymers by the radical process in the presence of optically active additives such as menthol and menthanthiol. ${ }^{18}$ These additives function as optically active chain transfer reagents. The prevailing one-handed helical polymers are produced because the chain transfer rates of the growing radicals with a right- or left-handed helicity to an optically active transfer reagent can be different, and the helical polymer with a larger transfer constant has a lower chance to propagate into the high molecular weight polymer compared with the opposite helical polymer with a lower transfer constant. On the other hand, acrylamides and methacrylamides with an amide proton cannot usually be polymerized by the anionic polymerization with alkyl lithiums and Grignard reagents. ${ }^{19}$ Actually, the anionic polymerization of TrMAM did not proceed using $n$-BuLi in toluene at $-78^{\circ} \mathrm{C} .{ }^{7}$ However, a prevailing one-handed helical poly(TrMAM) has been obtained by the radical polymerization in the presence of $(+)$ - or (-)menthol. Therefore, a systematic study of this asymmetric polymerization was performed using various optically active additives.

During the polymerization of the TrMA derivatives, a chiral cobalt (II) complex, $(1 S, 2 S)-N, N^{\prime}$-bis[3-oxo-2(2,4,6-trimethylbenzoyl)butylidene]-1,2-diphenylethylenediaminato cobalt(II) ((S)-MPAC) effectively controlled the polymer helicity. ${ }^{20}$ The results of the radical polymerization of TrMAM using ( $S$ )-MPAC are summarized in Table III. Pyridine was added for activating the Co complex. Although the Co system is useful for the polymerization of the TrMA derivatives to induce a one-handed helicity, ${ }^{20}$ it worked as a poly- 
Table III. Radical polymerization of TrMAM in the presence of $(S)$-MPAC in $\mathrm{THF}^{\mathrm{a}}$

\begin{tabular}{ccccc}
\hline Run & $\begin{array}{c}\text { Temp. } \\
\left({ }^{\circ} \mathrm{C}\right)\end{array}$ & $\begin{array}{c}{[(S)-\mathrm{MPAC}]} \\
(\mathrm{mol} / \mathrm{L})\end{array}$ & $\begin{array}{c}{[\mathrm{Py}]} \\
(\mathrm{mol} / \mathrm{L})\end{array}$ & $\begin{array}{c}\text { Yield }^{\mathrm{b}} \\
(\%)\end{array}$ \\
\hline 1 & 0 & 0.015 & 0.46 & $-^{\mathrm{c}}$ \\
2 & 0 & 0.035 & 0.46 & $-^{\mathrm{c}}$ \\
3 & 0 & 0.055 & 0.46 & $-^{\mathrm{c}}$ \\
4 & 0 & 0.055 & 0 & $-^{\mathrm{c}}$ \\
5 & 60 & 0.015 & 0.46 & $-^{\mathrm{c}}$ \\
\hline
\end{tabular}

${ }^{\mathrm{a}}[\mathrm{TrMAM}]_{0}=0.5 \mathrm{~mol} / \mathrm{L},[\mathrm{AIBN}]_{0}=0.02 \mathrm{~mol} / \mathrm{L}$, Initiator: AIBN with UV irradiation (Runs 1-4), AIBN (Run 5). ${ }^{\mathrm{b}} \mathrm{MeOH}-$ insoluble part. ${ }^{\mathrm{c}}$ Not polymerized.

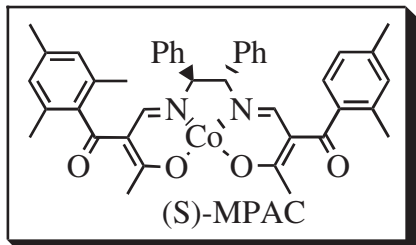

Table IV. Radical polymerization of TrMAM in a mixture of chiral additive and toluene at $0{ }^{\circ} \mathrm{C}^{\text {a }}$

\begin{tabular}{rcccc}
\hline Run & $\begin{array}{c}{[\text { TrMAM }]_{0}} \\
(\mathrm{~mol} / \mathrm{L})\end{array}$ & $\begin{array}{c}\text { Chiral additive/toluene } \\
(\mathrm{v} / \mathrm{v})\end{array}$ & $\begin{array}{c}\text { Yield }^{\mathrm{b}} \\
(\%)\end{array}$ \\
\hline 1 & 0.5 & $\mathbf{1}$ & $1 / 3$ & 0 \\
2 & 0.5 & $\mathbf{2}$ & $1 / 3$ & 0 \\
3 & 0.36 & $\mathbf{3}$ & $1 / 2$ & 63 \\
4 & 0.5 & $\mathbf{4}$ & $1 / 1$ & 86 \\
5 & 0.5 & $\mathbf{5}$ & $1 / 1$ & 86 \\
6 & 0.29 & $\mathbf{6}$ & $1 / 3.8$ & 52 \\
7 & 0.5 & $\mathbf{7}$ & $1 / 1$ & 53 \\
8 & 0.38 & $\mathbf{8}$ & $1 / 1.8$ & 31 \\
9 & 0.5 & $\mathbf{9}$ & $1 / 1$ & 77 \\
10 & 0.5 & $\mathbf{1 0}$ & $1 / 1$ & 85 \\
11 & 0.5 & $\mathbf{1 1}$ & $1 / 3$ & (THF) \\
12 & 0.5 & $\mathbf{1 2}$ & $1 / 4$ (THF) & 50 \\
13 & 0.47 & $\mathbf{1 3}$ & $1 / 2.3$ (THF) & 87 \\
14 & 0.47 & $\mathbf{1 4}$ & $1 / 1.2$ & 75 \\
15 & 0.44 & $\mathbf{1 5}$ & $1 / 1.4$ (THF) & 97 \\
16 & 0.50 & $\mathbf{1 6}$ & $1 / 1 \quad$ (THF) & 50 \\
17 & 0.50 & $\mathbf{1 7}$ & $1 / 1$ & 81 \\
\hline
\end{tabular}

${ }^{\mathrm{a}}[\mathrm{TrMAM}]_{0} /[\mathrm{AIBN}]_{0}=25$, time: $24 \mathrm{~h}$, initiator: AIBN/ UV. ${ }^{\mathrm{b}} \mathrm{MeOH}$-insoluble part.

merization inhibitor for TrMAM.

Table IV shows the results of the polymerization of TrMAM in the presence of various optically active alcohols and acids. Toluene or THF was also added to dissolve TrMAM. The radical polymerizations proceeded in most cases except for Runs 1 and 2, in which 2-butanol and 2-heptanol were used, respectively. Although these two runs were repeated, no polymer was obtained. The cause for this inhibition effect by these two alcohols is not clear at present.

The obtained polymers were not soluble in the common organic solvents, therefore, the $\mathrm{CD}$ spectrum was

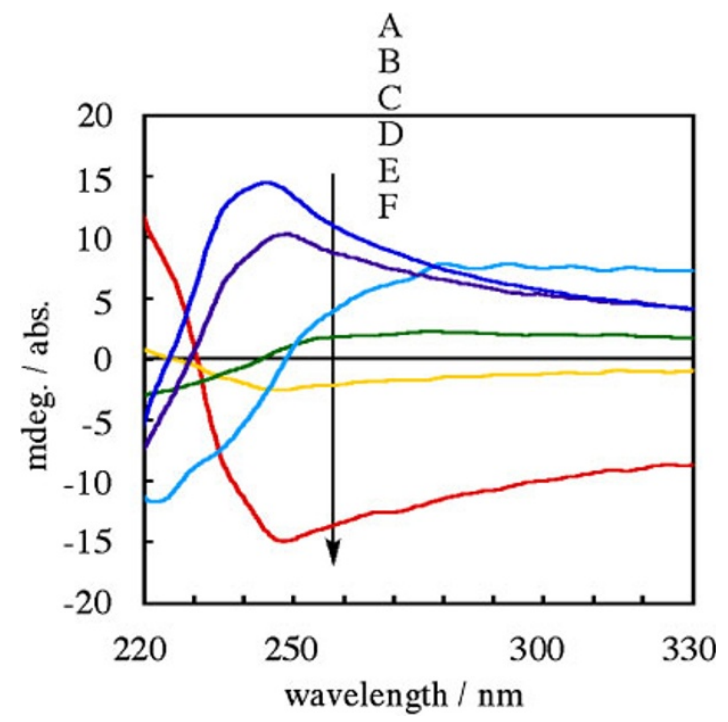

Figure 6. CD spectra of optically active PTrMAMs obtained in the presence of chiral alcohol or carboxylic acid (A: Run 4, B: Run 7, C: Run 3, D: Run 8, E: Run 14, F: Run 5 in Table IV) (in liquid paraffin at r.t.).

measured in the solid state for the polymer samples dispersed in liquid paraffin after grinding the polymer into small particles in a mortar. ${ }^{13}$ As shown in Figure 6, some of the poly(TrMAM)s (Runs 3-5, 7, 8 , and 14 in Table IV) exhibit CD absorptions. The CD intensities have been calibrated by the UV intensities, and the polymers obtained using (+)- or (-)menthol (Runs 4 and 5 in Table IV) exhibit the most intense CD absorptions. The CD peaks were also observed for the polymers prepared in the presence of other optically active alcohols and carboxylic acids. The CD pattern of the polymer obtained with $(R)-2-$ octanol (3) is different from others. This suggests that the polymer obtained in the presence of $\mathbf{3}$ may have a different helical structure.

The polymerization of TrMAM was carried out in the presence of the diastereoisomers of menthol $(4$ and 5), (+)-neomenthol (NM) and (+)-isomenthol (IM). These results are summarized in Table V. Toluene was added to obtain homogeneous solutions for $\mathrm{NM}$ at low temperatures, and THF was used for (+)-IM because of its low solubility in toluene. Polymers were formed in all cases.

Figure 7 shows the CD spectra of the polymers obtained at $0{ }^{\circ} \mathrm{C}$. The polymer obtained with (+)-IM showed no CD peak. This may be because that THF prevents the chirality induction by (+)-IM or (+)IM is ineffective for the chirality induction. On the other hand, the polymers obtained in the presence of $(+)$-NM, (+)-menthol, and (-)-menthol were optically active. The helix-sense-selectivity of (+)-NM seems to be similar to that of (-)-menthol.

The temperature effect on the chirality induction of 
Table V. Radical polymerization of TrMAM in the presence of stereoisomers of menthol ${ }^{\mathrm{a}}$

\begin{tabular}{crllcc}
\hline Run & $\begin{array}{c}\text { Temp. } \\
\left({ }^{\circ} \mathrm{C}\right)\end{array}$ & $\begin{array}{c}\text { Chiral additive/solvent } \\
(\mathrm{v} / \mathrm{v})\end{array}$ & {$[\text { TrMAM }]_{0}$} & $\begin{array}{c}\text { Yield }^{\mathrm{b}} \\
(\%)\end{array}$ \\
\hline 1 & -40 & $(+)-\mathrm{NM} /$ Toluene & $5 / 2$ & 0.22 & 84 \\
2 & -20 & $(+)-\mathrm{NM} /$ Toluene & $5 / 2$ & 0.22 & 42 \\
3 & 0 & $(+)-\mathrm{NM} /$ Toluene & $5 / 2$ & 0.22 & 50 \\
4 & 0 & $(+)-\mathrm{IM} / \mathrm{THF}$ & $1 / 2.3$ & 0.47 & 91 \\
5 & 20 & $(+)-\mathrm{NM} /$ Toluene & $5 / 2$ & 0.22 & 85 \\
\hline
\end{tabular}

${ }^{\mathrm{a}}[\mathrm{TrMAM}]_{0} /[\mathrm{AIBN}]_{0}=12.5$ (Run 1), 25 (Runs 2-7), initiator: $n$-Bu 3 B/air (Run 1), AIBN/UV (Runs 2-7), time: $48 \mathrm{~h}$ (Run 1), 24 h (Runs 2-7). ${ }^{\text {b }} \mathrm{MeOH}$-insoluble part.
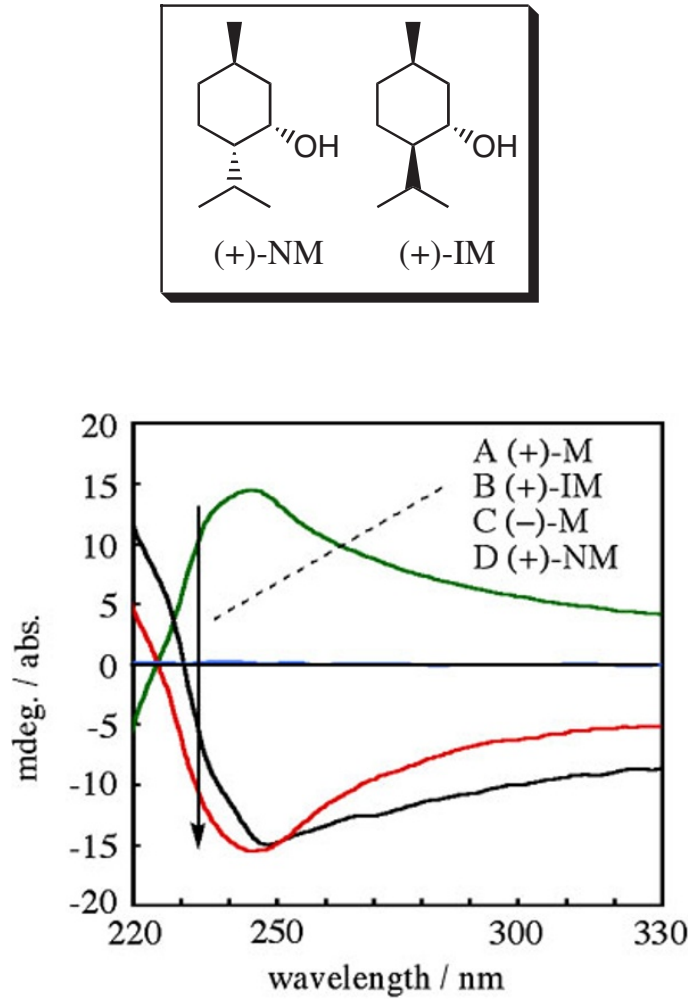

Figure 7. CD spectra of optically active PTrMAMs obtained at $0{ }^{\circ} \mathrm{C}$ (A: Run 4 in Table IV, B: Run 4 in Table V, C: Run 5 in Table IV, D: Run 3 in Table V) (in liquid paraffin at r.t.).

the polymerization in the presence of $(+)-\mathrm{NM}$ is shown in Figure 8. The poly(TrMAM) obtained at $0{ }^{\circ} \mathrm{C}$ (D: Run 3 in Table V) showed the highest CD intensity. At $-40^{\circ} \mathrm{C}$, the chain transfer to (+)-NM may occur to a less extent, and at -20 and $20^{\circ} \mathrm{C}$, it may proceed with a lower selectivity of the helicity.

\section{Chiral Recognition by Optically Active Poly(TrMAM)}

The chiral recognition ability of the optically active poly(TrMAM) obtained with (+)-menthol, (-)-menthol, and (+)-NM was evaluated using a chiral adsorption method. ${ }^{12}$ trans-Stilbene oxide and Tröger's base were used as the racemates (Table VI), because these two often show a high enantioselectivity and are easily analyzed by chiral HPLC. Each racemate was ad-

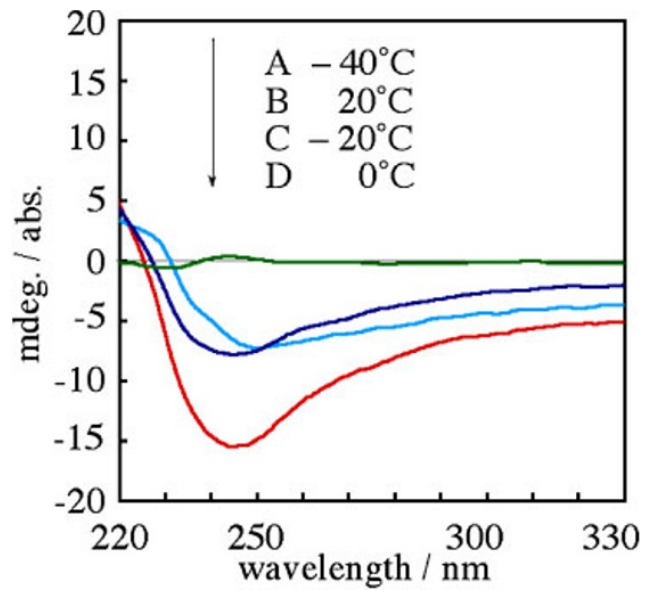

Figure 8. CD spectra of optically active PTrMAMs obtained in a mixture of $(+)$-neomenthol and toluene $(5 / 2(\mathrm{v} / \mathrm{v}))(\mathrm{A}$ : Run 1, B: Run 5, C: Run 2, D: Run 3 in Table V) (in liquid paraffin at r.t.).

sorbed by $c a$. $30-40 \%$ on the optically active poly(TrMAM) in methanol or isooctane. The enantiomeric excess (e.e.) of the free solutes in a supernatant solution was estimated by HPLC using a chiral column. Although the e.e. was very low, the excess enantiomers were reversed depending on the chirality of the polymer. This suggests that the data are sufficiently reliable. The low enantioselectivity of the poly(TrMAM)s compared to that of the one-handed helical poly(TrMA) may be due to the low one-handedness of the polymers. However, we cannot exclude the possibility of the low enantioselectivity for the polymer with a high one-handedness.

\section{Solvolysis of TrMAM}

The one-handed helical poly(TrMA) exhibits a high chiral recognition ability for many racemate. ${ }^{6}$ However, the poly(TrMA) is easily solvolyzed by alcohols or acids used as the eluent for HPLC. ${ }^{21}$ The half-life time of TrMA in a methanol-chloroform (1:1) mixture at $35^{\circ} \mathrm{C}$ is only $c a .15 \mathrm{~min} .{ }^{22}$ TrMAM was not solvolyzed even after one week under the same conditions. This clearly indicates that the amide group is more stable against the solvolysis than the ester group. Therefore, poly(TrMAM) should show a much higher durability against the solvolysis when used as a chiral stationary phase for HPLC.

\section{CONCLUSIONS}

The poly(TrMAM) and poly(DBuTrMAM) obtained by radical polymerization at low temperatures had nearly a $100 \%$ isotacticity. The poly(DBuTrMAM) showed a lyotropic crystalline phase in chloroform, and the isotactic poly(MAM) derived from the poly(TrMAM) showed a high crystallinity. The radical 
Table VI. Chiral recognition by optically active PTrMAMs at r.t. ${ }^{\mathrm{a}}$

\begin{tabular}{|c|c|c|c|c|c|}
\hline $\begin{array}{c}\text { Polymer } \\
\text { (Chiral additive) }\end{array}$ & Solvent & $\begin{array}{l}\text { Racemate } \\
\text { (Analyte) }\end{array}$ & $\begin{array}{l}\text { Adsorbed } \\
\text { analyte }^{\text {b }} \\
(\%)\end{array}$ & $\begin{array}{l}\text { E.E. of free analyte } \\
\text { in supernatant }{ }^{b} \\
\text { solution }(\%)\end{array}$ & $\begin{array}{l}\text { Separation } \\
\text { factor }(\alpha)^{\mathrm{c}}\end{array}$ \\
\hline \multirow{4}{*}{$\begin{array}{c}1 \\
((+)-M e n t h o l)\end{array}$} & \multirow{2}{*}{$\mathrm{MeOH}$} & 1 & 30 & $(+) 0.2$ & 1.01 \\
\hline & & 2 & 38 & $(-) 1.5$ & 1.08 \\
\hline & \multirow{2}{*}{ Isooctane } & 1 & 39 & (+) 0.5 & 1.02 \\
\hline & & 2 & 40 & $(-) 0.4$ & 1.01 \\
\hline \multirow{4}{*}{$\begin{array}{c}2 \\
((-)-M e n t h o l)\end{array}$} & \multirow{2}{*}{$\mathrm{MeOH}$} & 1 & 30 & $(-) 0.7$ & 1.04 \\
\hline & & 2 & 38 & $(+) 0.5$ & 1.02 \\
\hline & \multirow{2}{*}{ Isooctane } & 1 & 42 & $(-) 0.2$ & 1.00 \\
\hline & & 2 & 40 & $(+) 1.1$ & 1.05 \\
\hline \multirow{4}{*}{$\begin{array}{c}3 \\
((+)-\text { Neomenthol })\end{array}$} & \multirow{2}{*}{$\mathrm{MeOH}$} & 1 & 28 & $(-) 0.1$ & 1.00 \\
\hline & & 2 & 36 & (+) 0.3 & 1.02 \\
\hline & \multirow{2}{*}{ Isooctane } & 1 & 39 & $(-) 0.2$ & 1.01 \\
\hline & & 2 & 38 & $(+) 0.6$ & 1.03 \\
\hline
\end{tabular}

a Experimental conditions: optically active PTrMAM (obtained in a mixture of $(+)$-menthol, $(-)$-menthol, or $(+)$-neomenthol/toluene $=5 / 2(\mathrm{v} / \mathrm{v})$ at $\left.0{ }^{\circ} \mathrm{C}\right) 20 \mathrm{mg}$; racemic analyte $0.05 \mathrm{mg}(200 \mu \mathrm{L}$ portion from a $0.25 \mathrm{mg} / \mathrm{mL}$ solution in methanol, hexane/IPA $(=95 / 5)$, hexane and iso-octane. ${ }^{\mathrm{b}}$ Determined by HPLC analysis of supernatant solution using a Chiralcel OD columun. ${ }^{\mathrm{c} C a l c u l a t e d}$ according to $\alpha=\left(\mathrm{F}_{\text {major }}(\%) /\right.$ $\left.\mathrm{F}_{\text {minor }}(\%)\right) /\left(\mathrm{A}_{\text {major }}(\%) / \mathrm{A}_{\text {minor }}(\%)\right)$.

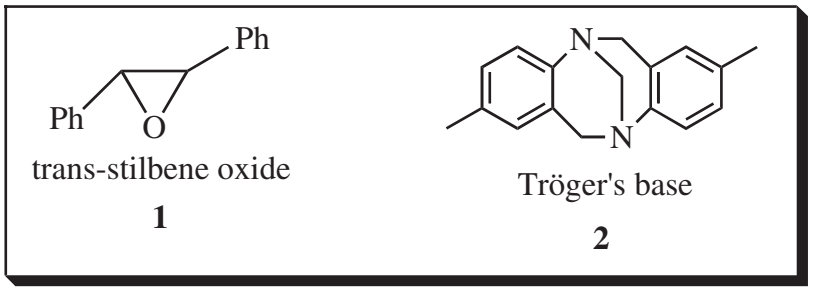

polymerization of TrMAM in optically active alcohols or carboxylic acids afforded the optically active polymer. The poly(TrMAM) obtained in the presence of $(+)$-neomenthol showed the most intense CD absorption. The chiral recognition ability of the optically active poly(TrMAM) was low, probably due to the low one-handedness of the polymer. TrMAM was much more stable against the solvolysis in a mixture of methanol-chloroform (1:1) than TrMA.

Acknowledgment. This study was supported in part by the 21st Century COE Program "Nature-Guided Materials Processing" and a Grant-in-Aid for Scientific Research (B) No. 14350485 by the Ministry of Education, Culture, Sports, Science and Technology, Japan. We appreciate Mr. Yu Miura for his assistance in preparing the manuscript.

\section{REFERENCES}

1. a) P. Pino and U. W. Suter, Polymer, 17, 977 (1976).

b) H. Yuki and K. Hatada, Adv. Polym. Sci., 31, 1 (1979).

c) K. Hatada, T. Kitayama, and K. Ute, Prog. Polym. Sci., 13, 189 (1988).

2. a) T. Nakano and Y. Okamoto, in "Controlled Radical Polymerization,” K. Matyjaszewski, Ed., ACS Symposium
Series, Vol. 685, American Chemical Society, Washington, DC, 1998, chapt. 27, p 451.

b) T. Nakano and Y. Okamoto, Macromol. Rapid Commun., 21, 603 (2000).

c) S. Habaue and Y. Okamoto, Chem. Rec., 1, 46 (2001). d) A. Matsumoto, in "Handbook of Radical Polymerization,” K. Matyjaszewski and T. P. Davis, Ed., John Wiley and Son's, New York, N.Y., 2002, chapt. 13, p 691.

3. a) K. Yamada, T. Nakano, and Y. Okamoto, Proc. Jpn. Acad. B, 74, 46 (1998).

b) K. Yamada, T. Nakano, and Y. Okamoto, Macromolecules, 31, 7598 (1998).

c) K. Yamada, T. Nakano, and Y. Okamoto, J. Polym. Sci., Part A: Polym. Chem., 37, 2677 (1999).

d) Y. Okamoto, K. Yamada, and T. Nakano, in "Controlled/ Living Radical Polymerization Progress in ATRP, NMP and RAFT," K. Matyjaszewski, Ed., ACS Symposium Series, Vol. 768, American Chemical Society, Washington, DC, 2000, chapt. 4, p 57.

4. a) Y. Isobe, D. Fujioka, S. Habaue, and Y. Okamoto, J. Am. Chem. Soc., 123, 7180 (2001).

b) S. Habaue, Y. Isobe, and Y. Okamoto, Tetrahedron, 58, 8205 (2002).

c) Y. Suito, Y. Isobe, S. Habaue, and Y. Okamoto, J. Polym. Sci., Part A: Polym. Chem., 40, 2496 (2002).

d) Y. Isobe, Y. Suito, S. Habaue, and Y. Okamoto, J. Polym. Sci., Part A: Polym. Chem., 41, 1027 (2003).

e) B. Ray, Y. Isobe, S. Habaue, M. Kamigaito, and Y. 
Okamoto, Polym. J., 36, 728 (2004).

f) B. Ray, Y. Okamoto, M. Kamigaito, M. Sawamoto, K. Seno, S. Kanaoka, and S. Aoshima, Polym. J., 37, 234 (2005).

5. a) H. Yuki, K. Hatada, T. Niinomi, and Y. Kikuchi, Polym. J., 1, 36 (1970).

b) Y. Okamoto, M. Ishikura, K. Hatada, and H. Yuki, Polym. J., 15, 851 (1983).

c) T. Nakano, M. Mori, and Y. Okamoto, Macromolecules, 26, 867 (1993).

6. a) H. Yuki, Y. Okamoto, and I. Okamoto, J. Am. Chem. Soc., 102, 6356 (1980).

b) Y. Okamoto, S. Honda, I. Okamoto, H. Yuki, S. Murata, R. Noyori, and H. Takaya, J. Am. Chem. Soc., 103, 6971 (1981).

c) T. Nakano, J. Chromatogr., A, 906, 205 (2001).

7. N. Hoshikawa, Y. Hotta, and Y. Okamoto, J. Am. Chem. Soc., 125, 12380 (2003).

8. J. Furukawa, T. Tsuruta, and S. Inoue, J. Polym. Sci., 26, 234 (1957).

9. A. K. Rappé and W. A. III Goddard, J. Phys. Chem., 95, 3358 (1991).

10. S. L. Mayo, B. D. Olafson, and W. A. III Goddard, J. Phys. Chem., 94, 8897 (1990).

11. Cerius2 User's reference Release 1.0, MSI.

12. T. Nakano, Y. Satoh, and Y. Okamoto, Polym. J., 30, 635 (1998).

13. F. Toda, H. Miyamoto, S. Kikuchi, F. Nagami, and R. Kuroda, J. Am. Chem. Soc., 118, 11315 (1996).

14. K. Hatada, T. Kitayama, and K. Ute, Polym. Bull., 9, 241 (1983).

15. A. K. M. F. Azam, M. Kamigaito, and Y. Okamoto, Polym. J., 38, 1035 (2006).
16. L. Cavallo, P. Corradini, and M. Vacatello, Polym. Commun., 30, 236 (1989).

17. a) Y. Okamoto, K. Suzuki, K. Ohta, K. Hatada, and H. Yuki, J. Am. Chem. Soc., 101, 4763 (1979).

b) Y. Okamoto and T. Nakano, Chem. Rev., 94, 349 (1994).

c) T. Nakano and Y. Okamoto, Chem. Rev., 101, 4013 (2001).

18. T. Nakano, Y. Shikisai, and Y. Okamoto, Polym. J., 28, 51 (1996).

19. a) Y. Okamoto, M. Adachi, H. Shohi, and H. Yuki, Polym. J., 13, 175 (1981).

b) Y. Okamoto, H. Hayashida, and K. Hatada, Polym. J., 21, 543 (1989).

c) K. Shiohara, S. Habaue, and Y. Okamoto, Polym. J., 28, 682 (1996).

d) S. Habaue, K. Shiohara, T. Uno, and Y. Okamoto, Enantiomer, 1, 55 (1996).

e) K. Shiohara, S. Habaue, and Y. Okamoto, Polym. J., 30, 249 (1998).

f) T. Uno, K. Shiohara, S. Habaue, and Y. Okamoto, Polym. J., 30, 352 (1998).

g) Y. Amano and Y. Okamoto, Polym. J., 37, 629 (2005).

20. a) T. Nakano and Y. Okamoto, Macromolecules, 32, 2391 (1999).

b) T. Nakano, K. Tsunematsu, and Y. Okamoto, Chem. Lett., 31, 42 (2002).

21. Y. Okamoto, E. Yashima, M. Ishikura, and K. Hatada, Polym. J., 19, 1183 (1987).

22. a) Y. Okamoto, H. Mohri, and K. Hatada, Polym. J., 21, 439 (1989).

b) T. Nakano, A. Matsuda, M. Mori, and Y. Okamoto, Polym. J., 28, 330 (1996). 